Artigo

\title{
NEOLIBERALISMO E EDUCAÇÃO: UM ESTUDO DE CASO SOBRE NUCLEAÇÃO ESCOLAR EM BOM JESUS DA LAPA
}

\author{
Edleuza de Jesus Batista Barbosa \\ Helder Freitas do Bomfim
}

\begin{abstract}
RESUMO
O trabalho tem como foco compreender como o processo de nucleação da Escola Municipal Nossa Senhora Aparecida, na cidade de Bom Jesus da Lapa - BA, e se organiza através das estratégias de gestão e integração da nova comunidade escolar. Investigou-se como a escola nucleada se organiza para garantir a democratização escolar diante da heterogeneidade de alunos. Os referenciais metodológicos que orientaram a pesquisa são qualitativos; foram realizados 24 questionários e 8 entrevistas de aprofundamento para construção dos dados. Com as observações de campo, buscou-se refletir sobre os conflitos e desafios do processo de nucleação, como o deslocamento físico e simbólico dos estudantes das comunidades rurais e quilombolas. A partir das análises da pesquisa, constatou que o processo de nucleação não contribui com o desenvolvimento do ensino-aprendizagem dos estudantes. Assim, destacou que esse processo dificulta o trabalho do professor e o desenvolvimento do estudante, como também provoca o desenraizamento dos estudantes de suas comunidades, de suas culturas e, sobretudo, a causa da insegurança dos pais e a preocupação com o deslocamento dos seus filhos.
\end{abstract}

\begin{abstract}
The work focuses on understanding how the nucleation process of the Municipal School Nossa Senhora Aparecida, in the city of Bom Jesus da Lapa - BA, and is organized through the management and integration strategies of the new scalar community. It was investigated how the nucleated school is organized to guarantee school democratization in view of the heterogeneity of students. The methodological frameworks that guided the research are qualitative; 24 questionnaires and 8 in-depth interviews were conducted to construct the data. With field observations, we sought to highlight the conflicts and challenges of the nucleation process, such as the physical and symbolic displacement of students from rural and quilombola communities. Based on the research analysis, it was found that the nucleation process does not contribute to the development of students' teaching-learning. Thus, he stressed that this process hinders the work of the teacher and the development of the student, but also causes the uprooting of students in their communities, their cultures and, above all, the cause of parents' insecurity and the concern with the displacement of their children.
\end{abstract}

Palavras-chave: Escola. Gestão Democrática. Nucleação.

Keywords: School. Democratic management. Nucleation.

\section{INTRODUÇÃO}

Esse artigo é um desdobramento de uma pesquisa realizada sobre a nucleação da Escola Municipal Nossa Senhora Aparecida na cidade de Bom Jesus da Lapa - BA. A pesquisa é uma investigação na área da Pedagogia correlacionando gestão escolar com os estudos acerca do processo de 
nucleação. A análise é uma reflexão sobre os desafios postos pela nucleação, em especial no que diz respeito à integração dos estudantes oriundos das comunidades rurais e quilombolas. Essa análise se dá sob um objeto que é multifacetado e articulado ao tema da gestão escolar, projeto político pedagógico e diversidade cultural.

O primeiro desafio deste trabalho é a compreensão que a questão da educação na contemporaneidade, tempos de globalização, neoliberalismo e mercantilização da educação. As pesquisas de Cristian Laval (2004, p.11) denunciam que a escola neoliberal designa certo modelo de políticas educacionais de ataque ao ensino público, considerando a educação como um bem, essencialmente, privado. As mutações provocadas pelo neoliberalismo desencadeiam em um conjunto de readequações do modelo de organização da educação. Dardot e Laval (2016) reiteram que o neoliberalismo transformou profundamente o capitalismo, impacta dano profundamente nas sociedades. O neoliberalismo não é apenas uma ideologia, um tipo de política econômica, é um sistema normativo que ampliou sua influência em escala global, estendendo a lógica do capital a todas as relações socais e a todas as esferas da vida.

Nos últimos anos vêm ocorrendo no Brasil, o processo de nucleação escolar, perpassando por todo país e regiões, inclusive no interior da Bahia, destacando os trabalhos de Sales (2007) relata sobre a educação rural brasileira limites e possibilidades do processo de nucleação em patos de Minas. Rodrigues e Marques et al. (2017) relata sobre a Nucleação de Escolas no Campo: conflitos entre formação e desenraizamento. Xavier e Cortez (2012) discutem sobre as implicações do processo de nucleação e a questão do transporte escolar na comunidade Lapinha e adjacentes em Bom Jesus da Lapa/BA. Carvalho e Alves (2017) aborda sobre a Política Pública de Nucleação das escolas rurais no Brasil e especialmente de escolas rurais de Guanambi, BA.

Segundo o Instituto Brasileiro de Geografia e Estatística (IBGE), censo de 2010, a população de Bom Jesus da Lapa é de 63.480 e a estimada 68.609 , com 43.099 urbana e 20.381, rural. Segundo a Secretaria de Educação de Bom Jesus da Lapa, existem 62 escolas municipais, sendo 34 rurais e 28 urbanas. De acordo com o decreto $\mathrm{n}^{\circ} 026$, de 15 de fevereiro de 2018, a cidade de Bom Jesus da Lapa - BA, totaliza 15 escolas nucleadas, sendo 13 rural e duas na sede. Após a nucleação, ficaram paralisadas 19 escolas, sendo 17 no campo e duas na cidade.

É importante destacar que, apesar dessa prática existir, fazendo parte da política pública do estado, essa temática ainda é pouca discutida na literatura. Diante do levantamento da pesquisa nas plataformas (catálogos de teses e dissertações da capes pode constatar que existe 12 dissertações e 7 teses que discutem a temática de nucleação na educação. Os principais trabalhos são estudos de caso sobre o processo em várias cidades do Brasil.

Apesar dessa problemática ainda ser pouco discutida no espaço acadêmico, o processo de nucleação já é investigado na área da pedagogia, mas ao levantar o estado da arte do tema, na biblioteca da UNEB Campus XVII observa-se a escassez de pesquisas sobre o tema aqui na cidade. Foi identificado somente o TCC realizado por Xavier e Cortez (2012), sobre as implicações do transporte escolar no processo de nucleação. Desse modo, a realização dessa pesquisa foi importante por permitir aprofundar o estudo 
sobre a questão da gestão durante o processo, e servirá como informação e contribuição para os futuros pesquisadores e professores interessados nos temas da gestão democrática e da nucleação no território Velho Chico.

Os estudos sobre a gestão escolar democrática na escola, abordam que esse processo é um princípio que deve reger a gestão, com ações e atitudes por meio da promoção da participação social. Segundo Cária e Santos (2014, p.27) esse debate se difundiu na educação pública nacional no período constituinte e durante a atualização da Lei de Diretrizes e Bases da Educação Nacional, em 1996. Fontana (2011, p.4) afirma que a gestão democrática é ancorada no processo de construção do espaço público, através da integração da comunidade, superando 0 individualismo e a educação excludente, promovendo igualdade, através da inter-relação da diversidade.

O grande desafio dessa pesquisa é refletir sobre a democratização da escola, em meio a um processo de nucleação. Segundo Sales (2007, p.75), nos últimos anos várias escolas passaram a ser nucleadas, "As escolas nucleadas se caracterizam por agrupar várias escolas isoladas em uma central [...] Esse modelo de nucleação surgiu nos Estados Unidos e foi implantado no Brasil em 1976". Os estudos sobre a educação no campo no Brasil e, em especial, na Bahia como destaca o trabalho de Carvalho, Alves, et al (2017) ao apontar que o processo de nucleação tem como intuito reunir várias escolas, em uma única escola, e dessa forma contribuiu para o fechamento das escolas no campo. Em decorrência desse processo de nucleação, o transporte escolar é o único meio que esses alunos encontram para ter acesso à escolarização, enfrentando o desgaste físico, estrada em condição de trafego péssimo, onde representa uma exaustiva jornada, entre outras questões.

É importante ressaltar que a nucleação escolar é um fenômeno recente na cidade de Bom Jesus da Lapa. Situação que demanda a realização de pesquisas cientifica para acompanhamento e avaliação de seus resultados. Vale ressaltar que a Constituição da República Federativa do Brasil de 1988 no seu artigo $5^{\circ}$ menciona que "todos somos iguais perante a lei, sem distinção de qualquer natureza..."dessa forma compreende-se que é dever do Estado garantir e proteger a diversidade cultural e dessa forma é indispensável ter um olhar diferenciado na perspectiva do ensino que contemple a diversidade de alunos. A escolha dessa temática surgiu no intuito de compreendermos, de modo específico, como a escola trabalha com a diversidade e a integração dos alunos do campo e da cidade. Diante disso, este artigo parte da seguinte questão: quais os principais desafios decorrentes do processo de nucleação da Escola Municipal Nossa Senhora Aparecida na cidade de Bom Jesus da Lapa?

Essa pesquisa apresentou por objetivo a compreensão do processo de nucleação através das estratégias de gestão e integração da nova comunidade escolar. O texto está dividido em quatro seções, além da introdução e considerações finais. A primeira intitulada "Contexto e método da pesquisa", apresenta a Escola onde foi realizado o estudo e escolhas metodológicas da pesquisa. A segunda seção chamada "Neo liberalismo e a educação no Brasil", é uma reflexão teórica sobre políticas educacionais em tempos de neoloberalismo e globalização no Brasil. A terceira seção "O processo de nucleação em Bom Jesus da Lapa" é apresentado uma análise crítica do caso em estudo. A quarta seção, são apresentados os achados das pesquisas é intitulada como "Os desafios da Gestão Democrática no processo de 
nucleação" E por fim, nas conclusões, são retomadas a questão de partida, e sistematizando o resultado da pesquisa.

\section{CONTEXTO E MÉTODO DA PESQUISA}

A Escola Municipal Nossa Senhora Aparecida foi fundada no ano de 1965, por uma professora leiga ${ }^{1}$, a senhora Manoelina Maria de Jesus, conhecida carinhosamente no bairro como "Neca", in memoriam. Hoje, a unidade escolar atua na modalidade de ensino regular, com anos iniciais do ensino fundamental; anos finais do ensino fundamental e Educação de Jovens e Adultos - EJA2. Estão matriculados cerca de 480 alunos, nos turnos matutino, vespertino e noturno, distribuídos nas seguintes (etapa e modalidade) - fundamental I, fundamental II e EJA.

Os referenciais metodológicos que orientaram a pesquisa são qualitativos; foram realizados 24 questionários e 8 entrevistas de aprofundamento para construção dos dados. Com as observações de campo, buscou-se compreender os conflitos e desafios do processo de nucleação. $O$ processo de aplicação do questionário se deu no espaço da escola. Para melhor compreensão e identificação do corpo discente da instituição pesquisada, fez-se necessária a construção de um instrumento capaz de inquirir sobre questões, tais como: idade, sexo, cor, religião, endereço e meio de transporte utilizado para chegar à escola. Com esse instrumento, buscamos reconhecer a participação em projetos na escola; a participação no grêmio estudantil; assim como, a identificação com conteúdos e experiências sobre discriminação.

Dos dados obtidos na pesquisa qualitativa consiste na codificação de registro de observação, entrevistas e análise de documentos. A técnica de análise de conteúdo incide em organização dos conteúdos que permite organizar, ordenar, transcrever e categorizar os dados, possibilitando uma análise mais profunda. A partir da utilização dessa técnica de análise, foi possível identificar o perfil da comunidade escolar, compreender o processo de nucleação e apresentar os resultados da pesquisa.

Para compreender os principais conflitos no processo de nucleação foi de fundamental importância a realização de entrevista com a diretora, coordenadora, duas professoras da escola, duas mães e duas estudantes da comunidade Quilombola de Lagoa do Peixe. No que diz respeito à análise das entrevistas, foi perceptível a frequência da questão das dificuldades associadas ao deslocamento de alunos.

O processo de análise do conteúdo se deu, verificando qualitativamente os dados fornecidos pelos entrevistados nas entrevistas, classificando-os e as

\footnotetext{
1 É o profissional que exerce o magistério sem possuir a habilitação mínima exigida. Segundo o Thesaurus do Instituto Nacional de Estudos Pedagógicos - INEP, do Ministério de Educação MEC, trata-se da pessoa que trabalha como docente, sem ter terminado o curso necessário que lhe permita obter o título correspondente ao nível de ensino em que leciona. São pessoas que lecionam sem ter concluído o curso que as habilitam ao exercício do magistério no nível de ensino em que atuam.

2 Segundo a Leis de Diretrizes e bases educacionais a Organização da Educação Brasileira de dá em Níveis e Modalidades, sendo eles educação básica (Educação infantil, creche 0-3 anos - Pré Escola 4-5 anos; Fundamental I, $1^{\circ}-5^{\circ}$ ano; Fundamental II $6^{\circ}-9^{\circ}$ ano; Ensino Médio) Educação superior (Graduação, Pós Graduação Stricto Sensu, Pós Graduação lato Sensu) Modalidades (Educação de Jovens e Adultos, Educação a distância, Educação especial, Educação profissional, Educação indígena e quilombola).
} 
categorias por significados próximos em um processo de codificação. As análises dos dados permitiram a construção de três grandes tipos de dificuldades apresentadas pelos diferentes interlocutores, são elas: deslocamento físico e simbólico dos estudantes das comunidades; relação família x escola e a discriminação racial. Entretanto será objeto deste artigo somente os desafios provocados pelo deslocamento físico e simbólico dos estudantes das comunidades.

\title{
O NEOLIBERALISMO E A EDUCAÇÃO NO BRASIL
}

O século XIX é tido como um divisor de águas na história do mundo ocidental. Os intérpretes da época associam a esse período, o que se convencionou como a modernidade. O "novo", o moderno se configurou um conjunto de transformações em dimensões sociais, econômicas, políticas e culturais. Do ponto de vista político e econômico é o momento de propagação do liberalismo de diversos países, tais como: Estados Unidos, e alguns da Europa e, em meio à construção dos princípios da sociedade capitalista. Dentre as principais defesas e bandeiras de "novidades" colocadas à sociedade ocidental, destaca-se a centralidade do ideal de liberdade individual, com base nos campos político-cultural e socioeconômicos. De acordo com Santos e Andrioli.

\begin{abstract}
O liberalismo surgiu e se desenvolveu nos séculos XVII e XVIII em oposição à monarquia absoluta, esta, fundada na ideia de hierarquia divina, social e natural, baseada na estrutura feudal de produção, bem como numa concepção teocrática do poder. Baseado na ideia de que os seres humanos são, por natureza, livres e iguais, o direito liberal rompe com a ideia de direito divino do monarca e, portanto, com a hierarquia estabelecida. O exemplo clássico deste rompimento foi a Revolução Francesa em 1789. Em lugar de uma submissão cega ao poder e à vontade do rei, criou-se a noção de direito civil, onde há regras (leis $=$ direito positivo) que valem para todos privilegiando o indivíduo, sua liberdade e seu direito natural à propriedade. Nasce o Estado liberal, com a função de legislar e garantir a ordem pública. (SATOS; ANDRIOLI, 2010, p.6).
\end{abstract}

Podemos perceber que esse sistema do liberalismo rompe com a ideia de hierarquia divina, com 0 intuito de defender o direito civil, tendo como propósito de legislar e organizar as questões referentes à produção econômica. Hoje, vivemos um processo de transformação do liberalismo expandido e reestruturado por um conjunto de contribuições teóricas e fatos empíricos, como as crises econômicas do século XX. Segundo Neto e Campos (2017, p.4) "O neoliberalismo que impera no mundo com maior expressão a partir dos anos 1990 desempenha uma influência direta sobre a educação". Essa ideologia neoliberal tem como papel anular as ações do estado, considerando mais o mercado com o enxugamento do papel do estado Estado.Dessa forma, compreende-se, que 0 neoliberalismo e a globalização são fatores preponderantes para compreensão das desigualdades sociais, haja vista que a educação passa a ser vista como uma mercadoria. Santos Andrioli ressalta que: 
Globalização significa a predominância da economia de mercado e do livre mercado, uma situação em que o máximo possível é mercantilizado e privatizado, com o agravante do desmonte social. Concretamente, isso leva ao domínio mundial do sistema financeiro, à redução do espaço de ação para os governos - os países são obrigados a aderir ao neoliberalismo - ao aprofundamento da divisão internacional do trabalho e da concorrência e, não por último, à crise de endividamento dos estados nacionais. (SANTOS; ANDRIOLI 2010, p.3).

Segundo Sousa (2010, p.3) "a tendência da globalização é subordinar todas as ações da sociedade aos interesses corporativos das grandes empresas transnacionais [...]". Para tanto, a globalização é um processo que faz uma ligação global com relação à mundialização do capital, e, dessa forma, uma abertura do intercâmbio comercial. Neto e Campos fizeram a seguinte ressalva sobre as características do sistema.

\begin{abstract}
ideologia neoliberal: reforma do estado; desestatização da economia; privatização das empresas produtivas e lucrativas governamentais; abertura dos mercados; redução dos encargos sociais relativos aos trabalhadores por parte do poder público e das empresas ou corporações privadas; informatização dos processos decisórios produtivos de comercialização e outros; busca da qualidade total; intensificação da produtividade e da lucratividade da empresa ou corporação nacional ou transnacional. (NETO ; CAMPOS, 2017, p.7)
\end{abstract}

Nesse sentido, percebemos que o neoliberalismo e a globalização, ambos têm suas raízes no sistema capitalista internacional, onde os mesmos impõem as regras e um modelo de organização da economia mundial. Neto e Campos (2017, p.01) apontam que "o cidadão que deveria ser educado para uma visão de interesse geral, referenciada com direitos humanos na limitação de suas ações, é educado pelo interesse do Estado", marcado pelo individualismo e colonizado pelos interesses particulares. Percebe-se, assim, que esse sistema capitalista está preocupado com a formação do ser humano, visando à produção do capital a serviço do mercado e da empresa capitalista. Basso e Neto ressaltam que:

[...] as contradições sociais geradas pelo neoliberalismo, a pauperização, aumento da violência e exclusão social. Contudo, é preciso termos certos cuidados com o termo exclusão social, visto que os indivíduos não são retirados da sociedade e de suas influências, na verdade, quando falamos em exclusão social, estamos nos referindo à falta de acesso aos bens sociais, ou seja, educação, saúde, seguridade social, entre outros. (BASSO e NETO 2014, p.5).

Essa ideia tem como propostas a valorização da força de trabalho, qualificar o sujeito para a mão de obra. Nesse processo os sujeitos são subordinados a opressão dessa doutrina que acreditam que a formação educacional deva estar voltada para o mercado de trabalho, onde será fundamental para a produtividade e desenvolvimento. Desta maneira, a 
literatura aponta que a educação ainda é um sistema reprodutor dessas desigualdades.

A escola neoliberal designa um certo modelo escolar que considera a educação como um bem essencialmente privado e cujo valor é, antes de tudo, econômico. Não é a sociedade que garante a todos os membros um direito à cultura, são os indivíduos que devem capitalizar recursos privados cujo rendimento futuro será garantido pela sociedade. Essa privatização é um fenômeno que afeta, tanto o sentido do saber, as instituições transmissoras dos valores e dos conhecimentos quanto as próprias relaçoes sociais. (LAVAL (2004,p.11).

Diante disso, percebe-se que apesar de as Leis garantirem o acesso à educação como direito, elas não garantem as condições necessárias para a permanência dos estudantes na escola.Dessa forma, compreende-se que o sistema neoliberal impõe uma camada de consequências sobre a educação, como as desigualdades sociais, o analfabetismo, o desemprego, a violência, a alienação e a pobreza. Que basicamente são relacionadas com as questões da saúde e muitos outros efeitos, como as reformas do ensino, visando uma educação voltada para o setor profissionalizante, o fechamento de escolas, a aceleração, a privatização do ensino e a nucleação.

\section{O PROCESSO DE NUCLEAÇÃO EM BOM JESUS DA LAPA}

Como dito, este trabalho tem como foco compreender como o processo de nucleação da Escola Municipal Nossa Senhora Aparecida, na cidade de Bom Jesus da Lapa - BA, e se organiza através da compreensão das estratégias de gestão e integração da nova comunidade escolar. Investigou-se como a escola nucleada se organiza para garantir a democratização escolar diante da heterogeneidade de alunos. De acordo com Sales (2007, p.75). "As escolas nucleadas se caracterizam, por agrupar várias escolas insoladas em uma central, afim de fornecer subsídios adequados para a concretização de uma educação tida como eficiente, também cumprindo com seu papel social".

Com a nucleação, além de atender às necessidades dos moradores do Bairro Lagoa Grande, a escola passa a atender alunos das comunidades rurais, tais como Fazenda Bom Sucesso, Juazeirão e Fazenda Campos. Conforme notaram Silva e Hespanhol (2016 p. 362), "[...] que em várias regiões do Brasil utiliza-se a terminologia "comunidade rural" para designar um grupo de pessoas que vive nas áreas rurais e que partilham dos mesmos eventos, tradições e costumes".

A escola também acolheu estudantes das comunidades quilombolas, Lagoa do Peixe, Barrinha, Cariacá e Araçá. Segundo as Diretrizes Curriculares Estaduais para Educação Escolar Quilombola, em seu artigo 3ํㅡㄹ define as comunidades quilombolas como "os grupos étnico-raciais definidos por autoatribuição, com trajetória histórica própria, dotados de relações territoriais específicas, com presunção de ancestralidade negra, relacionada com a resistência à opressão histórica".

Além desses, outros estudantes provenientes das comunidades ribeirinhas da Ilha do Carrapato e Mariquinha, também participaram. Segundo (GUARIM 2000, p.13). "Os ribeirinhos, são seres humanos instalados às 
margens dos rios, desenvolvem permanentemente uma estreita relação com o ambiente, o qual se manifesta numa intensa interação". Houve ainda, a participação de alunos, moradores de bairros adjacentes (comunidades urbanas) como Shangrilá e Parque Verde. As comunidades urbanas são conceituadas, segundo Corrêa, (2011.p1) "local de concentração de atividades comerciais, de serviço e de gestão; áreas industriais e áreas residenciais, distintas em termos de forma e conteúdo social; áreas de lazer; entre outras, aquelas de reserva para futura expansão". Assim, percebe-se que, comunidade.

De acordo com projeto político pedagógico, a escola Municipal Nossa Senhora Aparecida foi fundada no ano de 1965 pela professora Mandolina Maria de Jesus. Essa escola teve início embaixo de uma árvore, chamada juazeiro e, nos períodos de chuva funcionava em na residência da referida professora. A escola já funcionou em alguns lugares alugados pela prefeitura municipal, até sua sede ser construída, em 1997. O local onde funciona atualmente a escola já foi ampliado três vezes para atender às demandas dos alunos, os quais são oriundos das comunidades rurais, como Juazeirão, Barrinha, Ilha da Mariquinha, Quilombo, Lagoa do Peixe, Bom Sucesso, AraçáCariacá e Fazenda Campos. A escola hoje atende a 480 estudantes, sendo 280 das comunidades rurais. Esses alunos são distribuídos no ensino fundamental I, no ensino fundamental II e na Educação de Jovens e Adultos. O processo de nucleação, teve início a partir do ano de 1997, quando a escola ganhou o seu espaço próprio e recebeu os estudantes oriundos das comunidades rurais e quilombolas.

Do que diz respeito ao processo de nucleação, destacamos que, para a gestão pública, a nucleação se justifica como uma estratégia de economia orçamentária. Segundo, Xavier e Cortez (2012, p.27) enfatizam que "por um lado, a nucleação para os municípios é considerada como um grande avanço, uma vez que minimizando os custos de funcionamento, otimizando os recursos disponíveis nas escolas". Com o fechamento das escolas do campo contribuiu para o deslocamento dos alunos para as redes educacionais na cidade. Situação que ocasionam deslocamentos físicos, sociais e culturais.

Temos notado que o meio rural brasileiro sofre com a investida do capitalismo que há muito tempo, veio disfarçado de melhorias e desenvolvimento para a produção. Observamos cada vez mais a criação de motivos na tentativa de esvaziamento das comunidades camponesas. Fechar a escola da comunidade rural e levar os estudantes para as escolas do meio urbano tem gerado tensões, conflitos, divergências de opiniões entre as gestões municipais e os sujeitos organizados do campo, por esses últimos intenderem que tal política contribui para a desarticulação na dinâmica exercida pela escola que funciona dentro da comunidade, muitas vezes, construída pelos moradores. (CARVALHO; ALVES, 2017, P.04).

Diante disso, é perceptível como a população das comunidades rurais ainda é submissa pelos governantes, pois eles não levam em consideração a forma de ensino exercida pelas comunidades. Partindo desse argumento, percebemos o descaso com os estudantes campesinos em que eles são 
obrigados a si deslocarem para a cidade em busca de escolarização. Nota-se que essa política não propõe melhorias e qualidade de ensino, mas sim, uma política de redução de gastos e desvalorização da educação do campo.

Além disso, acrescenta-se também o "desenraizamento" dos estudantes dos seus territórios. Segundo Rodrigues e Marques, et al. (2017, p. 04) "Desvincular as crianças e os jovens da comunidade e da escola pode provocar o desenraizamento da cultura local e de pertença ao grupo. A escola não pode negar a cultura local e a pertença a um grupo social com suas particularidades".Com relação ao que foi posto anteriormente, observa-se que, esse processo de desvinculação dos estudantes da sua comunidade rural para estudar no meio urbano é negar o direito do estudante a ter uma educação vinculada com os saberes locais dos seus ancestrais, passada de geração a geração.

Nesse contexto, o processo de nucleação pode ser fator gerador de instabilidade rural, uma vez que deixa de considerar as especificidades das mesmas e o papel que a escola rural exerce nestas comunidades, já que, promovendo 0 deslocamento das crianças e adolescentes para estudar fora de suas comunidades de origem, pode alimentar o processo de desenraizamento dos mesmos com relação ao seu entorno. (XAVIER; CORTEZ, 2012, p. 27).

Os autores apontam que a escolarização não oferecida, na comunidade de pertencimento do estudante, leva o mesmo a negar sua própria identidade, sua territorialidade, 0 que implica no seu autorreconhecimento e reconhecimento do seu território. Segundo Rodrigues e Marques.

[...] o deslocamento das crianças e jovens das suas comunidades desvincula-os da sua vivência e cultura local, atribuindo novos valores, negando sua identidade, passandose a não considerar a comunidade como possibilidade de vida. (RODRIGUES; MARQUES, 2017, p.3).

Diante dessas percepções, entende-se que a retirada dos estudantes do seu contexto natural é negar os saberes dos seus antepassados, suas culturas, seus costumes e crenças. Assim, a educação oferecida em outra comunidade pode levar à perda desses valores, tanto para os estudantes, como também para as comunidades. É importante salientar que a educação brasileira ainda precisa ser repensada e levar em consideração as especificidades dos povos. Conforme, Carvalho e Alves.

A maioria das mudanças no modelo educacional brasileiro é baseada em influências de outros países e no caso da nucleação não foi diferente. Entretanto o que aparentemente é considerado influência de algo que acontece em outros países, na verdade faz parte de um projeto político econômico de sociedade, em que objetiva a manutenção de uma sociedade capitalista, altamente excludente. Assim, em nome de um suposto desenvolvimento, estabelece metas que dizem respeito exclusivamente ao fator econômico. (CARVALHO; ALVES, 2017, p.09). 
Considera se como princípio do processo de nucleação das escolas rurais as lacunas apresentadas na Lei 9.394/96, Lei de Diretrizes e Bases da Educação Nacional (LDB), como está explícito no seu artigo 11 que "os Municípios incumbir-se-ão de organizar, manter e desenvolver os órgãos e instituições oficiais dos seus sistemas de ensino, integrando-os às políticas e planos educacionais da União e dos Estados" LDB (2017, p.13).

Diante desse contexto, compreendemos que os governantes se apropriaram desta medida para adotar o sistema de nucleação com o intuito de acabar com as classes multisseriadas das escolas rurais. Entretanto, essa política de nucleação não passa de uma política de imposição que tira os direitos dos alunos de estudarem nas suas próprias comunidades. Carvalho e Alves fizeram a seguinte ressalva:

Esses argumentos nos levam à reflexão de como a educação no campo tem sido ignorada na história da educação brasileira, e como a identidade do povo do campo, assim como as suas vozes, são subjugadas na hora de decidir o melhor para si. As escolas que dão vida às comunidades estão se extinguindo e esse processo de extinção é um passo largo para a perpetuação da hegemonia capitalista no meio rural. (CARVALHO; ALVES, 2017, p.07).

De acordo com Sales (2007, p.59). "essa nova configuração necessita ser analisada para se tentar compreender até que ponto a nucleação se torna avanço ou retrocesso da função da escola no seio de uma determinada comunidade". Esse relato nos possibilita compreender que a educação precisa ser dialogada, refletida e analisada tendo em vista uma educação que contemple a todos dentro das suas especificidades a partir da realidade de cada comunidade.

Sabemos que a educação quando oferecida na comunidade de pertencimento do aluno, ela exerce uma função fundamental na reestruturação e organização, tanto do estudante como da própria comunidade. Para Molina e Jesus.

\footnotetext{
É tarefa específica da escola, ajudar a construir um Ideário que orienta a vida das pessoas e inclui também as ferramentas culturais de uma leitura mais precisa da realidade em que vivem. E ajudar a construir uma visão de mundo significa em primeiro lugar fazer o inventário das concepções que educandos e educadores carregam em si; significa também enraizar as pessoas na história, para que se compreendam como parte de um processo histórico. E isso tudo para tornar consciente, explicitar, interpretar, questionar, organizar, firmar ou revisar ideias convicções sobre o mundo, sobre a história, sobre a realidade mais próxima, sobre si mesmos. (MOLINA; JESUS, 2004, p.25).
}

Nesse caso, a política de nucleação visa um ensino descontextualizado da realidade e do modo de vida dos estudantes. Segundo Carvalho e Alves (2017, p.03) "[...] compreendendo que essa ação pública priva milhares de jovens de seu direito à escolarização, à formação como cidadãos e ao ensino que contemple e se dê em sua realidade e como parte de sua cultura". 
Podemos perceber que a prática de nucleação das escolas rurais e quilombolas se desenvolveu por todo o país e regiões, com o intuito de eliminar as escolas do campo com pequeno número de alunos matriculados.

A Lei de Diretrizes e Bases da Educação Nacional é que regulamento o processo educacional. Como argumenta Sales.

A constituição de 1988 coloca a educação como dever do estado, incluindo aí a educação rural. Entretanto, os projetos destinados a esse meio não são pensados de forma nacional, mas ficam a cargo das administrações locais, uma vez que o ensino fundamental se torna responsabilidade do governo municipal. Essa ideia vai ser reforçada com a promulgação da LDB 9.394 de 1996, que prevê a autonomia dos municípios para criarem seus próprios sistemas de ensino, o que dará uma característica local ao planejamento e efetivação de políticas para a educação rural. (SALES 2007, p.49).

Levando em conta os princípios da constituição, compreende que os administradores municipais são os principais responsáveis por adotar essa medida de economia educacional, assim como está previsto na constituição, cabe aos governantes decidir as políticas para as suas cidades. Nesse sentido, a ação educativa deve ser repensada levando em consideração as especificidades da população campesina como as comunidades tradicionais e comunidades rurais. Para tanto, Rodrigues e Marques et al, ressaltam que:

Essas especificidades, porém, não têm sido consideradas, pois se enfrenta um momento muito difícil na educação do campo com a concretização dos processos de nucleação, a qual tem funcionado praticamente como sinônimo de fechamento das escolas. (RODRIGUES; MARQUES ET AL. 2017, p.04).

Sabemos que as retiradas desses alunos das comunidades rurais para estudarem na cidade desvinculam-os dos seus saberes, costumes, cultura e o modo de vida, considerando uma desativação de pertencimento do seu território. Segundo Carvalho e Alves.

É necessário chamar atenção dos gestores que, caso a política de nucleação seja de fato necessária, esta deva ocorrer intracampo, ou seja, campo para campo, de modo que respeite questões referentes à distância e incluindo a comunidade nessa decisão. As políticas públicas construídas são ainda de caráter urbano e trazem a nucleação como solução para as deficiências no sistema de ensino. (CARVALHO; ALVES, 2017, p.03).

Apesar de existir documentos legais como o decreto $n^{\circ} 7.352$, de 4 de novembro de 2010 que dispõem sobre políticas públicas para a educação do campo e a resolução $\mathrm{CEE}^{3} / \mathrm{CEB}^{4} \mathrm{n}^{\circ} 68$ de $2^{\circ}$ de dezembro de 2013 denominada de Diretrizes Curriculares Estaduais para a Educação Escolar

\footnotetext{
${ }^{3}$ Conselho Estadual de Educação

${ }^{4}$ Conselho Estadual de Educação da Bahia
} 
Quilombola que garante ao estudante uma educação nas comunidades rurais, inclusive nas comunidades tradicionais, como as comunidades quilombolas.

Diante disso, ainda é perceptível a prática de agrupamentos de escolas numa escola núcleo e uso de transporte escolar sem monitores, somente com o motorista para dirigir e monitorar as crianças. Nesse contexto, constata-se, que essa política de nucleação posta por gestores municipais contradiz o que está sugerido pelos documentos que legitimam uma educação como direito de todos. Com base no exposto acima, compreende-se, que os povos das comunidades rurais são assegurados por leis que garantam a educação em suas comunidades. Entretanto, infere-se, que essas políticas estão sendo desenvolvidas de forma contraria. Segundo Molina (2011, p.192) "Assim, exclui-se do planejamento da ação pedagógica o essencial: o próprio campo e as determinações que caracterizam os sujeitos que vivem nesse território". Nesse sentido, entende-se o direito à educação no contexto analisado está sendo negado para os estudantes de comunidades rurais e tradicionais.

Dessa forma percebemos que a políticas de nucleação não favorece os estudantes e a comunidade escolar. Com base na revisão da literatura é possível perceber que a nucleação pode ser considera como uma expressão local de um fenômeno mais amplo nas políticas educacionais. De forma que a justificativa pela redução de custos é uma das características comum do neoliberalismo na educação. A colonização da lógica empresarial para deliberações políticas sobre a educação. Os desafios sobre esse processo serão objetos da seção a seguir.

\section{OS DESAFIOS DA GESTÃo DEMOCRÁtICA NO PROCESSO DE NUCLEAÇÃO}

O debate em torno da gestão democrática escolar vem surgindo ao longo do tempo, com o intuito de refletir sobre o papel da escola e sua função social. De acordo com Braga (2010, p.18) "a escola é forçada a pensar e repensar seu papel. Quando disposta a refletir, as mesmas passam a ter legitimidade exercendo a democratização da gestão, enquanto possibilidade de melhoria do processo educacional". Assim, a organização da prática escolar consiste por meio da gestão democrática escolar participativa.

A gestão democrática deve estar impregnada por uma certa atmosfera que se respira na escola, na circulação das informações, na divisão do trabalho, no estabelecimento do calendário escolar, na distribuição das aulas, no processo de elaboração ou de criação de novos cursos ou novas disciplinas, na formação de grupos de trabalho, na capacitação dos recursos humanos etc. A gestão democrática é, portanto, atitude e método. A atitude democrática é necessária, mas não suficiente. Precisamos de métodos democráticos, de efetivo exercício da democracia. A democracia também é um aprendizado, demanda tempo, atenção e trabalho. (GADOTTI,1998, p.18).

Nesse sentido, fica evidente que a gestão democrática é fundamental para o desenvolvimento educacional, onde deve ser organizada dentro de um processo que abrange a coletividade educacional, valorizando a participação de todos os funcionários da escola, inclusive pais e alunos. Portanto, é 
importante perceber a importância do trabalho coletivo, tendo como princípio a articulação e a organização do gestor escolar. A gestão democrática na escola é essencial para o desenvolvimento do processo ensino-aprendizagem, em que o aluno passará a ser o sujeito de sua aprendizagem, participando das decisões referentes ao projeto político pedagógico, que deverá ser elaborado junto com toda a comunidade escolar. Dessa forma, o projeto político pedagógico é quem determina a identidade da escola, sinalizando as inspirações como os objetivos e metas a alcançar.

O aluno aprende apenas quando se torna sujeito de sua aprendizagem. E para ele se tornar sujeito da sua aprendizagem precisa participar das decisões que dizem respeito ao projeto político pedagógico da escola, que faz parte também do projeto de sua vida. Passamos muito tempo na escola para sermos meros clientes dela. Não há educação e aprendizagem sem sujeito da educação e da aprendizagem. A participação pertence à própria natureza do ato pedagógico. (GADOTTI (1998, p, 17).

Nesse contexto, podemos compreender que a gestão democrática da escola é fundamental para o desenvolvimento educativo, onde o aluno deverá participar das decisões referentes ao projeto, uma vez que ele é um sujeito que irá passar o seu maior tempo nesse espaço. Dessa forma, a escola na atualidade é uma instituição que deverá ter uma gestão democrática a serviço da sociedade em que, ela é uma conquista da comunidade. O exercício da gestão participativa é fundamental para desenvolvimento do sistema educacional, tendo como princípio a participação da comunidade escolar, na perspectiva de resolver as dificuldades e os desafios existentes na instituição de ensino. Percebemos que, para o fortalecimento da organização educativa é essencial a participação coletiva de todos os que pertencem à comunidade escolar.

Assim, o processo de gestão escolar deve incorporar o exercício da participação coletiva da prática educacional, com a criação de instâncias participativas de deliberação, tais como, conselhos, grêmios e comissões técnicas.

\section{DESLOCAMENTO FíSICO E SIMBÓLICO DOS ESTUDANTES DAS COMUNIDADES RURAIS E QUILOMBOLAS}

No que se refere ao deslocamento físico dos estudantes das comunidades, a análise da questão da dificuldade foi recorrente nas entrevistas. Ao perguntar quais as dificuldades que o professor encontra para trabalhar em uma escola nucleada, o deslocamento físico foi central na contextualização dos professores. Abaixo, segue a fala de uma professora:

A dificuldade que eu vejo é sobre a falta do aluno porque, igual se eu passei um assunto hoje para vinte e faltou 3 ou 4 que é da zona rural, que não vieram, eu tenho que repor de novo para aqueles que não vieram. Porque nós temos que repor, se não eles vão ficar para traz e assim, se eu passar uma pesquisa se for da primeira chamada eu tenho que estender o tempo, são coisas assim que a gente ver. (Jane, 45 anos). 
No relato da primeira professora, nota-se que as dificuldades que ela acha é a falta do aluno, a perda dos conteúdos e o prejuízo em reposição de aulas. Dessa forma, percebe que, todos os alunos são prejudicados com relação ao processo de nucleação, tanto os alunos da zona urbana e, principalmente, os alunos das comunidades rurais. Ainda sobre a questão do deslocamento dos alunos para estudar na cidade, foi feito o seguinte questionamento para mãe e estudante: quais as implicações com relação ao processo de deslocamento e se interfere na aprendizagem. Vejamos o que mãe e estudante relataram:

Esse deslocamento interfere, porque às vezes tem hora que,
quando chega o final do ano mesmo, a criança já tem passado
2 meses sem estudar porque o ônibus quebra e fica aí as
crianças sem estudar fora da escola. Então por isso eu acho
que tem muita dificuldade. E as professoras não repõe mais os
assuntos perdidos. Um dia eu falei ela disse que não tinha mais
como as crianças acompanhar as crianças da zona urbana,
devido os tempos porque não tem mais como repor as aulas. E
meu filho perdeu o ano e isso não foi só um ano não, já foram
vários anos que é assim. O meu filho já perdeu três anos, foi
três anos que aconteceu isso. A dificuldade do ônibus é de
mais porque se a gente tivesse condição de ter uma escola na
comunidade eu acharia melhor, o deslocamento dificulta muito,
além de dificultar dar muita Preocupação nos pais. (Mãe Divina
53 anos);

Reitera a estudante,

A maioria dos trabalhos é em dupla ou em grupo, porque está em falta de livros. Mas tipo assim, como eu moro longe fica mil vezes mais difícil para me ajudar eles, porque eu tenho que ir para a escola de manhã cedo, aí fica um pouco mais difícil, aí se caso for em grupo, a gente combina na sala como fazer as coisas, a professora prefere passar mais na sala porque tem muitos que mora longe. (Estudante Beatriz, 14 anos).

Ainda no que se refere ao deslocamento, a aluna Tatiana 11 anos fez 0 seguinte relato "se tivesse escola aqui, eu preferia estudar aqui, porque ficaria mais perto. $E$ pode até acontecer acidente daqui para a escola é muito perigoso seria muito mais fácil estudar aqui". Assim, percebe-se na fala da aluna que a angústia dessa rotina de estudar fora do seu contexto da sua comunidade. A professora Jane relata que:

A gente tem que tentar de várias formas porque, a gente está vendo aí o discurso com a educação os alunos desistindo, ontem mesmo eu assistir uma reportagem falando que tem vários alunos que entram na universidade e não vão até o final, não tem condição de se manter, Igual o ônibus fica 10 dias sem pegar. Quem é o pai da zona rural que tem condição, que tem como mandar o filho dez dias o menino de moto taxi para a escola? (Professora Jane, 45 anos). 
Diante dessas entrevistas, percebemos que a nucleação de escolas provoca várias implicações, tanto com o que diz respeito ao trabalho do professor, como também aos estudantes e familiares. De acordo com Rodrigues e Marques et al (2017, p.4) para além da distância física, somada as péssimas condições da estrada, que tornam o deslocamento desconfortáveis e incômodos, "a nucleação das escolas do campo e o deslocamento para escolas distantes da sua comunidade desvinculam os sujeitos da sua forma de viver e da sua cultura, ou seja, de suas raízes". Nesse sentido, os estudantes além de se deslocarem de suas comunidades, ainda são submetidos a uma série de implicações.

Frente a esses desafios, a nucleação provoca também um deslocamento simbólico. Mas para melhor compreensão, questionei nas entrevistas sobre a relação identidade, diversidade e conteúdos trabalhados na sala.

A gente tem que organizar porque tem as Diretrizes
Quilombolas mesmo, mas nunca tivemos como trabalhar, na
escola, tem o programa mais educação e os alunos das
comunidades rurais não participam, eles são os que mais
precisa, não tem como eles estudarem aqui pela manhã e
voltarem à tarde. Nós procuramos trabalhar de forma
interdisciplinar. (Coordenadora Renata, 38 anos).

A partir da fala da coordenadora, pode-se observar a dificuldade de organizar a proposta de ensino, diante das especificidades e diversidades de estudantes. A estudante faz o seguinte relato sobre os conteúdos estudado, com relação aos seus conhecimentos. "Tem algumas coisas que é meio parecida com as daqui. Mas é muito difícil ela passar sobre isso. A disciplina de história é meio parecida por causa que ela fala muito do passado, do navio negreiro e como aconteceu as coisas sobre os negros, e aqui também já aprendi sobre isso. (Aluna Beatriz 14 anos). Entretanto, a aluna Tatiana respondeu que:

A Relação do conteúdo com os saberes da comunidade? Nenhuma. A disciplina de Educação Ambiental que fala muito do ambiente, para a gente preservar, as vezes a gente vai para a horta eu já levei quatro sacos de estercos para a horta, lá a gente aduba, limpa, e planta alface e muitas coisas lá. (Aluna Tatiana 11 anos).

Com base nos relatos das estudantes, pode ser percebido que os conteúdos são afastados dos seus saberes, com exceção de duas disciplinas que apresentam conteúdos meio parecidos com as realidades das estudantes.

\section{CONSIDERAÇÕES FINAIS}

O trabalho de campo no que se refere à gestão democrática escolar e o processo de nucleação foram realizados na escola Municipal Nossa Senhora Aparecida e permitiu que fosse possível, empiricamente, perceber que esse campo de análise requer grandes reflexões e investimentos de estudos. É necessário superar a banalidade do olhar sobre a operacionalização das políticas públicas de nucleação com criticidade. 
A análise desse trabalho permitiu perceber que a política de nucleação das escolas na Bahia é de interesse dos governantes e contrários aos interesses das comunidades. A literatura apontou que o sistema educacional brasileiro é colonizado pela adoção de modelos educacionais ligados aos interesses neoliberais. De acordo com Carvalho, Alves et al (2017, p.9), "[...] no caso da nucleação não foi diferente. [...] na verdade faz parte de um projeto político econômico de sociedade, em que objetiva a manutenção de uma sociedade capitalista, altamente excludente".

Apesar das Leis como o Estatuto da Criança e do Adolescente, Diretrizes Curriculares Quilombolas e Decreto n 7.352 , de dezembro de 2010, assegurar o direito da criança e adolescentes de ter acesso à escola pública próxima da sua residência, a realidade é muito diferente, pois os governantes preferem nuclear escolas e assim, superlotar as salas de aulas, dificultando a aprendizagem do aluno, comprometendo o trabalho do professor.

Dessa forma, uma decisão de gerenciamento político impacta diretamente na vida dos estudantes. $O$ acesso à educação só se dá a partir de deslocamentos físicos e simbólicos. A nucleação afasta a educação das comunidades, e para os estudantes lhe restam acessar a educação em escolas distantes de suas comunidades. Um cotidiano de deslocamentos, enfrentado desafios e dificuldades em busca da escolarização.

Diante dessa situação, do processo de nucleação de escolas, nota-se que as justificativas para adoção dessas políticas públicas que é eliminar as classes multisseriadas e melhoria do processo ensino-aprendizagem. Porém, a pesquisa realizada mostrou que as salas não são multisseriadas, todavia, são superlotadas.

Com os dados apresentados, ficou evidente a necessidade de refletir as questões sobre o sistema de imposição, com relação às políticas de nucleação de escolas. Para Carvalho, Alves et al (2017, p.13) "enquanto os processos de nucleação forem vistos como medidas para a redução de gastos, a educação oferecida aos povos do campo e da cidade tende a ser marginalizada pelo capital".

Diante disso, percebe-se que esse sistema de educação deve ser reavaliado e repensado, de forma democrática, garantir o direito de posicionamento das camadas que são subalternizadas nesse processo, uma vez que essas políticas são contrárias aos interesses das populações das comunidades tradicionais. Nesse sentido, a educação, quando oferecida fora do território de pertencimento do estudante, provoca o desenraizamento do estudante da sua comunidade e de suas culturas. Sabemos que a oferta da educação na cidade para os estudantes das comunidades tradicionais é um fator que contribui para essa desarticulação, provocando a evasão desses estudantes.

O distanciamento das propostas pedagógicas, com relação à realidade dos estudantes, pode ser pensado como uma violência simbólica. Assim, compreende-se que currículo é fundamental para a construção do conhecimento e para a valorização do sujeito. As políticas de nucleação não favorecem os estudantes e a comunidade escolar é possível perceber que a nucleação pode ser considera como uma expressão local de um fenômeno mais amplo nas políticas educacionais. De forma que a justificativa pela redução de custos é uma das características comum do neoliberalismo na educação. A colonização da lógica empresarial para deliberações políticas 
sobre a educação. Os desafios sobre esse processo serão objetos da seção a seguir.

A educação escolar deve, ainda, garantir aos alunos, o direito de se apropriarem dos conhecimentos tradicionais e histórico-culturais da comunidade. Dessa forma, vale também, possibilitar o conhecimento com base nas experiências dos estudantes e na história das comunidades de origem.

\section{REFERÊNCIAS}

BASSO Daniela, NETO Luiz Bezerra. As influências do neoliberalismo na educação brasileira: algumas considerações. Disponível em: $<$ https://www.revistas.ufg.br/rir/article/view/29044/17224>. Acesso em 08. Out. 2018

BRAGA, Luiz Ricardo Pereira de Almeida. A produção do sucesso na gestão escolar: organização Participação e democracia/Luís Ricardo Braga Pereira de Almeida-Bom Jesus da Lapa: UNEB/DCHT, 2010.

BRASIL, LDB. Lei 9394/96. Lei de Diretrizes e Bases da Educação Nacional. Disponível em<www.mec.gov.br>. Acesso em: 26. Set. 2018.

BRASIL, Presidência da República Decreto $n^{\circ} 7.352$ de 4 de novembro de 2010: dispõe sobre a Política Nacional de Educação do Campo e sobre o programa de Reforma Agrária. Disponível em <http://portal.mec.gov.br/docman/marco-2012-pdf/10199-8-decreto-7352-de4de-novembro-de-2010/file> Acesso em 04. Nov. 2918.

BRASIL, Constituição da República Federativa do Brasil, (1988). disponível em <http://www.planalto.gov.br/ccivil_03/Constituicao/Constituicao.htm>. Acesso em 08. Abr. 2019.

BRASIL, Decreto ํo 026, de 15 de fevereiro de 2018. Dispõe sobre a nucleação de unidades escolares localizadas na sede e no interior do município de Bom Jesus da Lapa. Disponível em <http://bomjesusdalapa.ba.gov.br/arquivos/publicacoes/203212201807031.doc x. Acesso em 22. Ago. 2018.

BRASIL. Diretrizes curriculares estaduais para a educação quilombola. Resolução CEE/CEB №68/ 2013, Salvador - BA, 2014.

CARVALHO, L. L.; ALVES. T.A.A. P.; LIMA, V. D.; TRINDADE, D.R. A Política Pública de Nucleação das escolas rurais no Brasil: apontamentos de pesquisas. Disponível em <http://periodicos.uesb.br/index.php/semgepraxis/article/viewfile/7368/7143> Acesso em 20. Set. 2018.

CÁRIA, Pena Neide; SANTOS, Mileide Pereira. Gestão e Democracia na Escola: limites e desafios. Disponível em $<$ https://periodicos.ufsm.br/regae/article/viewfile/13789/pdf_>. Acesso em 08. Out. 2018. 
CORRÊA Roberto Lobato. O espaço urbano disponível em<<http://reverbe.net/cidades/wp-content/uploads/2011/08/oespacourbano.pdf>. Acesso em 02. Out. 2018

DARDOT, Pierre. A nova razão do mundo: ensaio sobre a sociedade neoliberal/ Pierre Dardot; Christian Laval: tradução Mariana Echalar. 1 ed. São Paulo: Boitempo, 2016.

FONTANA, Andréia Regina. Gestão Escolar Democrática: é possível? Disponível

<www.ideau.com.br/getulio/restrito/upload/revistasartigos/147_1.pdf $>$. Acesso em 19.Set. 2018.

GADOTTI, Moacir. Projeto Político Pedagógico da escola cidadã. Salto para o futuro: construindo a escola cidadã, projeto político pedagógico/ Secretaria de educação a distância. Brasília: ministério da educação e do desporto, SEED, 1998.

GUARIM, Vera Lúcia, Sustentabilidade Ambiental em Comunidades Ribeirinhas Tradicionais. Disponível. em<http://riosvivos.org.br/wpcontent/uploads/2015/10/sustentabilidade_comuni dades.pdf> Acesso em 01. Out. 2018.

IBGE Instituto Brasileiro de Geografia e Estatista: disponível em<<https://cidades.ibge.gov.br/> Acesso em 07. Nov. 2018.

LAVAL, Christian, A escola não é uma empresa. O neoliberalismo em ataque ao ensino público. Christian Laval. trad. Maria Luiza M. de Carvalho e Silva. Londrina: Editora Planta, 2004.

MOLINA, Monica Castagna. Politicas Publicas, In: Trindade, A. C. Movimentos sociais e a luta pelo público na educação: escolas itinerantes no Brasil e bacharelados populares na Argentina. 2011. Dissertação (mestrado em educação) -faculdade de educação, Universidade Federal do rio de Janeiro, Rio de Janeiro, 2011.

MOLINA, Monica Castagna e Jesus Contribuições para a construção de um projeto de Educação do Campo / Mônica Castagna Molina e Sônia Meire Santos Azevedo de Jesus (organizadoras). Brasília, DF: Articulação Nacional "Por Uma Educação do Campo, 2004.

NETO, Filinto Jorge Eisenbach; CAMPOS Gabriela Ribeiro de. O impacto do neoliberalismo na educação brasileira. Disponível em <http://educere.bruc.com.br/arquivo/pdf2017> Acesso 14. Nov. 2018.

RODRIGUES A. C. S.; MARQUES, D. F.; RODRIGUES, A. M.; DIAS, G. L. Nucleação de Escolas no Campo: conflitos entre formação e desenraizamento. Disponível em: $<$ https://www.researchgate.net/publication/314220005_Nucleacao_de_Escolas 
no_Campo_conflitos_entre_formacao_e_desenraizamento>. Acesso em 14. Out. 2018.

SALES, Suze da Silva, A educação rural Brasileira: limites e possibilidades do processo de nucleação em patos de Minas, MG (1990-2002). Dissertação de Mestrado Universidade Federal de Uberlândia/ MG, 2007. Disponível em $<$ http://repositorio.ufu.br/bitstream/123456789/14086/1/Suze.pdf> Acesso em: 11. Set. 2018.

SANTOS, R.; ANDREOLI, A. I. Educação, Globalização e Neoliberalismo: o debate precisa continuar! Disponível em: $<$ https://www.google.com.br/search?q=educa globaliza neoliberalismo debate precisa continuar! > Acesso em 14. Nov. 2018.

SILVA, Juniele Martins. HESPANHOL, Rosangela Aparecida de Medeiros. Discussão sobre Comunidade e Características das Comunidades Rurais no $\begin{array}{lllll}\text { Município de } & \text { Catalão } & (\mathrm{GO}) & \text { disponível }\end{array}$ <http://www.scielo.br/pdf/sn/v28n3/1982-4513-sn-28-03-0361.pdf> Acesso em 15. Nov. 2018.

SOUSA, J.V.; RANGEL, M. L. Gestão Democrática e Avaliação Emancipatória: caminhos para uma educação superior de qualidade disponível< http://www.anpae.org.br/congressos_antigos/simposio2009/> Acesso em 07. Nov. 2018.

XAVIER, Eunice dos Santos. Implicações do processo de nucleação e a questão do transporte escolar na comunidade Lapinha e adjacentes em Bom Jesus da Lapa/BA/Eunice dos Santos Xavier; Rosineia Cruz Cortes. - Bom Jesus da Lapa, 2012. 